EESTI NSV TEADUSTE AKADEEMIA TOIMETISED. 28. KOIDE KEEMIA. 1979, NR. 2

ИЗВЕСТИЯ АКАДЕМИИ НАУК ЭСТОНСКОИ ССР. ТОМ 28 Химия. 1979, № 2

\title{
ПРОДУКТИВНОСТЬ СОТРУДНИКОВ НИИсланцев ПО НАУЧНЫМ ПУБЛИКАЦИЯМ (1958-1975 гг.)
}

Одним из важных компонентов научного потенциала научно-нсследовательского учреждения является продуктивность сотрудников по научным публикациям. Этот показатель позволяет, хотя и косвенно, проводить некоторые параллели между отдельными учреждениями одного профиля, сравнивать интенсивность их работы и отдачу, ибо большинство научных результатов реализуется в настоящее время в виде публикаций, авторских свидетельств и диссертаций. Правда, результаты прикладных исследований реализуются в виде публикаций в значительно меньшей степени, чем результаты фундаментальных работ. Они могут вылиться в исходные данные для проектирования и регламенты, опытные образцы и технологические схемы.

В нашей работе за основу расчетов принято количество публикаций, так как этот показатель, по нашему мнению, объективнее отражает продуктивность коллектива или отдельных ученых, чем объем публикаций. При этом в отдельной публикации излагаются обычно результаты уже законченного этапа работы.

Подсчету подлежали научные книги и брошюры, авторефераты диссертаций, авторские свидетельства, научные статьи, доклады и тезисы. В некоторых вариантах расчетов публикации сгруппированы в две подгруппы: книги и статьи. В группу «книги» мы включили книги, брошюры, авторефераты, поскольку они, в сушности, содержат информацию о результатах многолетних исследований (диссертации), а также авторские свидетельства, так как и в последних отражается глубокая, часто многолетняя проработка отдельного вопроса и обязателен фактор новизны. Такая работа не может не иметь большего значения, чем брошюра, которая в официальной книжной статистике СССР входит в рубрику «книги». В группе «статьи» учитываются научные статьи, доклады и тезисы.

Результативность работы сотрудников НИИсланцев по количеству научных публикаций разных типов в отдельные периоды показана в табл. 1, составленной на основе картотеки публикаций сотрудников НИИсланщев в библиотеке института и дополненной нами около 50 наименованиями и авторскими свидетельствами и $\left[^{1}\right]$. Монографии и брошюры составляют чрезвычайно ничтожную долю $(0,6 \%)$ от всех публикаций. На втором месте снизу стоят авторефераты $(3,5 \%)$, на третьем - авторские свидетельства $(6,6 \%)$. Даже если мы рассмотрим рубрику «книги» в более широком смысле, то в нее все равно войдет не более, чем $10,7 \%$ от всей научной продукции института. Кстати, в Институте химии АН ЭССР (ИХ) «книги» составляют 13,1 , в Тартуском госуниверситете (ТГУ) - 10,4\%, т. е. их процент там тоже сравнительно низкий. Основное количество научной продукции НИИсланцев - научные статььи. Институт со дня основания издает сборники своих трудов 

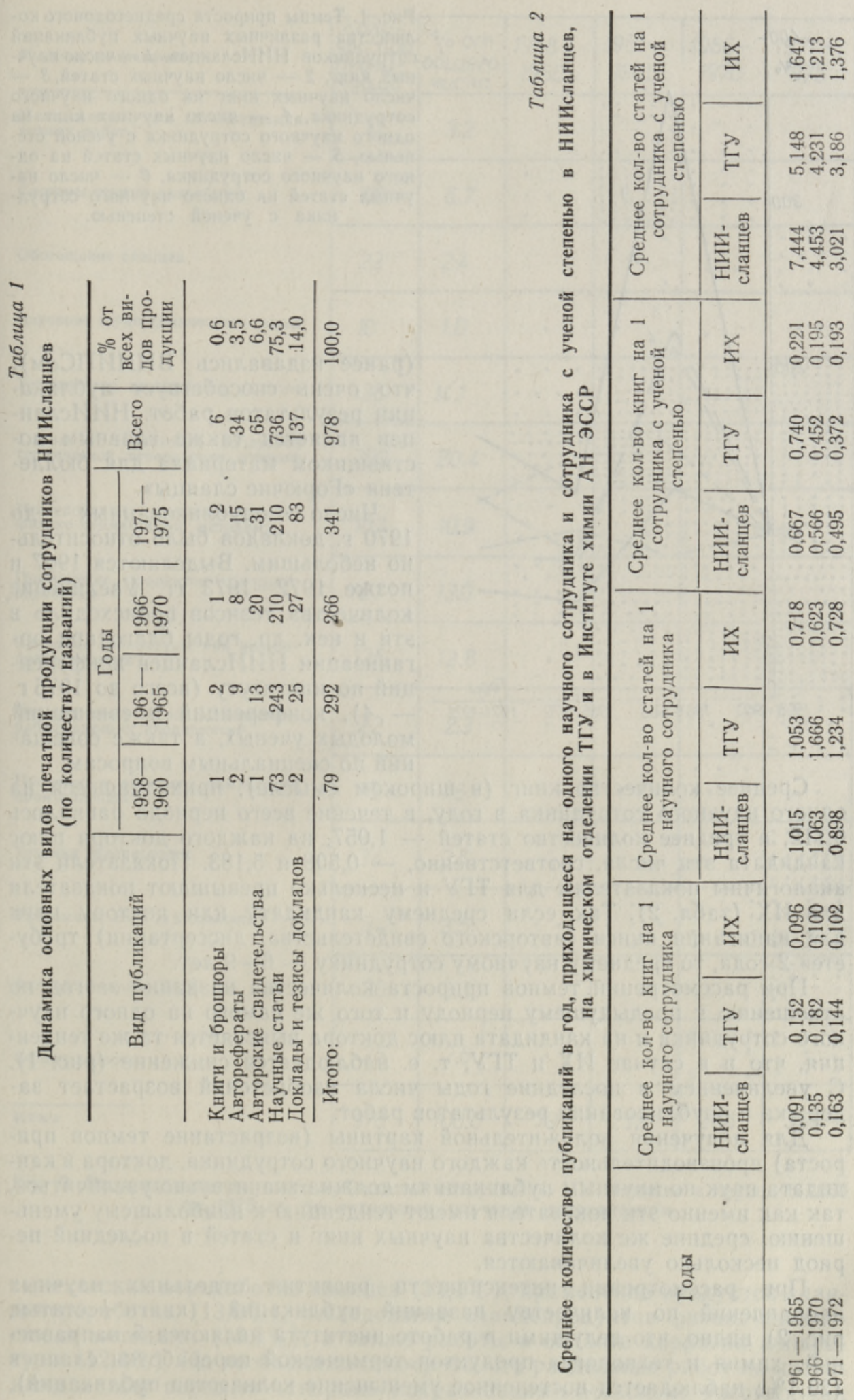


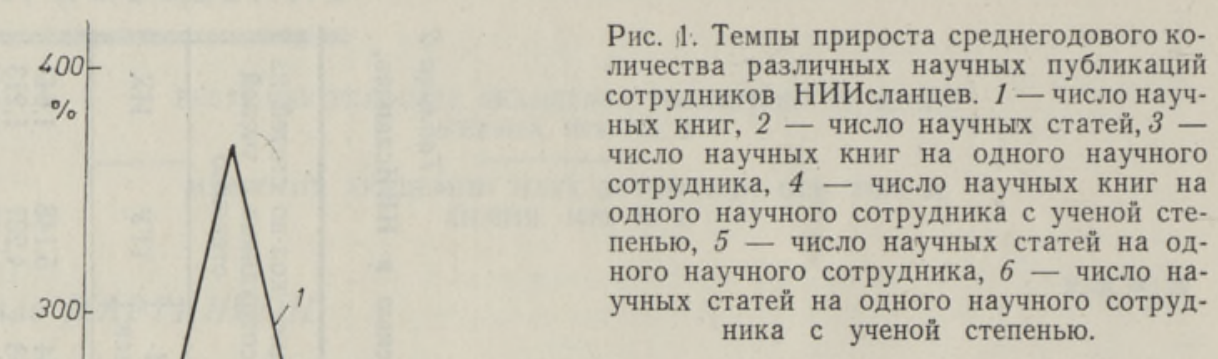

(ранее издавались ВНИИПСом), что очень способствует публикации результатов работ. НИИсланцев является также главным поставщиком материала для бюллетеня «Горючие сланцы».

Число опубликованных до 1970 г. докладов было относительно небольшим. Выделяются 1967 и позже 1972-1973 гг. Увеличение количества тезисов происходило в эти и нек. др. годы благодаря организации НИИсланцев конференций по институту (всего до 1975 г. - 4), конференций и совещаний молодых ученых, а также совещаний по специальным вопросам.

Среднее количество книг (в широком смысле), приходившееся на одного научного сотрудника в году, в течение всего периода равнялось 0,112 , а среднее количество статей - 1,057, на каждого доктора плюс кандидата эти числа, соответственно, - 0,508 и 5,183. Показатели эти аналогичны показателям для ТГУ и несколько превышают показатели для ИХ (табл. 2). Так, если среднему кандидату или доктору наук для написания книги (авторского свидетельства, диссертации) требуется 2 года, то среднему научному сотруднику - 6-9 лет.

При рассмотрении темпов прироста количества названий за год по отношению к предыдущему периоду и того же самого на одного научного сотрудника и на кандидата плюс доктора выясняется та же тенденция, что и в случае ИХ и ТГУ, т. е. наблюдается снижение (рис. 1). С увеличением в последние годы числа изобретений возрастает задержка в опубликовании результатов работ.

Для получения положительной картины (возрастание темпов прироста) производительность каждого научного сотрудника, доктора и кандидата наук по научным публикациям должна значительно увеличиться, так как именно эти показатели имеют тенденцию к наибольшему уменьшению, средние же количества научных книг и статей в последний период несколько увеличиваются.

При рассмотрении интенсивности развития отдельных научных направлений по количеству названий публикаций (книги + статьи, рис. 2) видно, что ведущими в работе института являются 5 направлений: химия и технология продуктов термической переработки сланцев (20,4\%; наблюдается постепенное уменьшение количества публикаций), 
Научное направление

Механизация и автоматизация горных работ

Системы горных разработок

Обогащение сланцев

Изученне горно-химического сырья

Термическая переработка сланцев

Химия и технология продуктов термической переработки сланцев

Исследование сланцепродуктов фнзико-хнмическими методами

Применение продуктов сланцепереработки

Коррозия аппаратуры при переработке сланцев

Очнстка сточных вод сланцеперерабатывающих предприятий

Процессы и аппараты химической промышленности

Техника безопасности

Экономика, НОТ и управление

Автоматизация и $\mathrm{ACy}$

Общие вопросы

Иroro

Рис. 2. Распределение научных публикаций сотрудников НИИсланцев в период с 1958 по 1975 гг. по отдельным научным направлениям.

термическая переработка сланцев $(14,1 \%)$, применение продуктов сланцепереработки $(13,0 \%)$, исследование сланцепродуктов физико-химическими методами $(10,9 \%)$, а также работы в области коррозии аппаратуры $(12,4 \%)$. Но необходимо оговорить, что разделение работ по названиям между первыми четырьмя направлениями несколько условно, так

\begin{tabular}{|c|c|c|c|c|c|}
\hline $\begin{array}{l}\text { Ko^u- } \\
\text { чec.nDo } \\
\text { nyoıu: } \\
\text { Kau,ü }\end{array}$ & $\begin{array}{c}\% \text { om } \\
\text { oduezo } \\
\text { чucıa }\end{array}$ & $\begin{array}{c}1558- \\
1960\end{array}$ & $\begin{array}{r}1961- \\
1965\end{array}$ & $\begin{array}{c}1966- \\
1970\end{array}$ & $\begin{array}{c}1971- \\
1975\end{array}$ \\
\hline 31 & 3.2 & & $\begin{array}{l}::::: \\
\vdots: \vdots::\end{array}$ & $\mid \begin{array}{ll}\cdot & 0 \\
. & - \\
\end{array}$ & \\
\hline 66 & 6.7 & $\begin{array}{lll}\cdot & & \\
. & \cdot & \cdot \\
. & & \cdot \\
\end{array}$ & 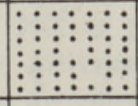 & $: \vdots:$ & \\
\hline 23 & 2.4 & & $\begin{array}{lll}\cdot & & \cdot \\
\cdot & \cdot & \cdot \\
\cdot & & \cdot \\
\end{array}$ & $\cdot \cdot$ & $: * \dot{:}$ \\
\hline 10 & 1.0 & • & $\begin{array}{ll}\cdot & \cdot \\
\cdot & \cdot \\
\end{array}$ & $\cdot \cdot$ & . \\
\hline 138 & 14.1 & $\begin{array}{lcc}\cdot & \cdot & \cdot \\
\cdot & \cdot & \cdot \\
. & \cdot & \cdot \\
\end{array}$ & 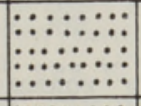 & 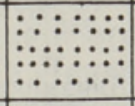 & $:$\begin{tabular}{l}
$:::: \vdots$ \\
$: \vdots \vdots$ \\
\hdashline$\vdots$ \\
\hdashline$: \vdots$ \\
\hdashline$:$
\end{tabular} \\
\hline 200 & 20.4 & $\because \therefore \therefore:$ & 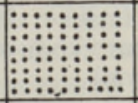 & 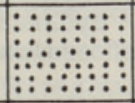 & 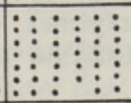 \\
\hline 107 & 10.9 & $\begin{array}{lll} & \cdot & \cdot \\
\cdot & \cdot & \\
\end{array}$ & $\because: \vdots: \vdots$ & 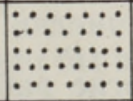 & 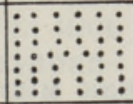 \\
\hline 127 & 13.0 & $\because \vdots \vdots \vdots$ & $\because \because \because \because:$ & $\because: Z: \geq:: \vdots$ & 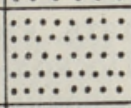 \\
\hline 125 & 12.8 & - & $\because \because: \because:$ & $::::::: \vdots \vdots:$ & 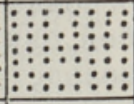 \\
\hline 22 & 2.3 & - & & - & $\because \vdots: \vdots$ \\
\hline 16 & 1.6 & $\cdot \cdot$ & . $\cdot$ & $\begin{array}{l}\cdots \\
\cdots \\
\dot{0}\end{array}$ & - $\cdot$ \\
\hline 34 & 3.5 & & . & - . & $\because \therefore: \vdots:$ \\
\hline 34 & 3.5 & . $\cdot$ & $\begin{array}{lll}\cdot & \cdot & \cdot \\
\cdot & \cdot & \cdot \\
\cdot & \cdot & \cdot \\
\end{array}$ & $: \vdots \vdots:$ & $: \quad: \quad:$ \\
\hline 20 & 2.0 & & & & $\vdots \vdots \vdots \vdots$ \\
\hline 25 & 2.6 & • & $\cdot$ & $\begin{array}{lll}\cdot & \cdot & \cdot \\
\cdot & \cdot & \cdot \\
\end{array}$ & $\vdots \vdots \vdots \vdots$ \\
\hline 978 & 100.0 & 79 & 292 & 266 & 341 \\
\hline
\end{tabular}




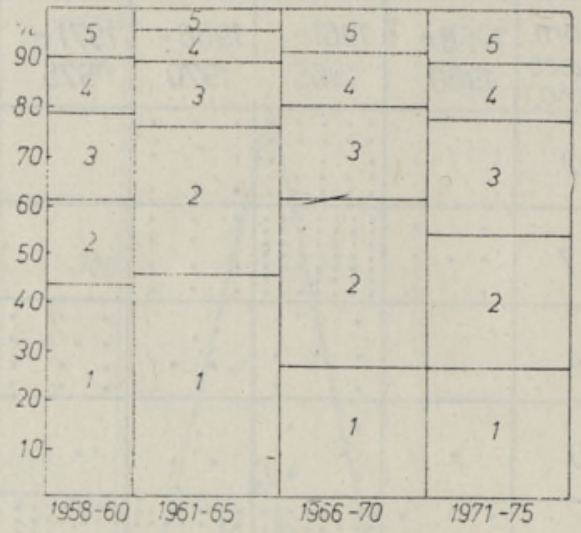

Рис. 3. Динамика коллективности в научных публикациях НИИсланцев (цифры обозначают количество авторов).

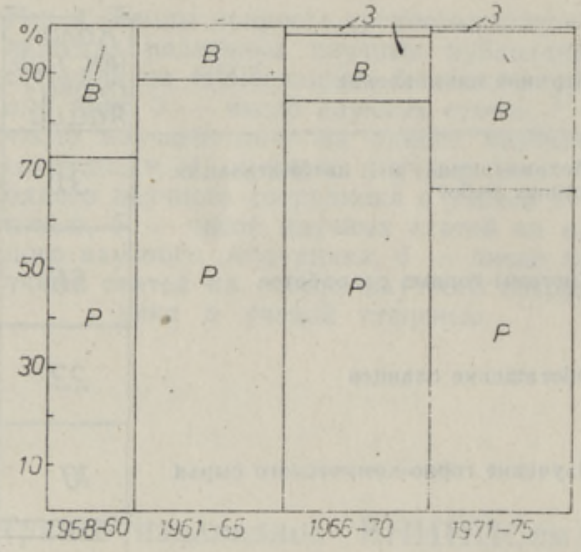

Рис. 4. Место публикации работ НИИсланцев. $P-$ в республиканской печати, $B-$ во всесоюзной печати, 3 - за границей.

как многие работы могли войти в ту или иную рубрику, и можно счигать, что эти направления между собой более или менее равноправны. Поскольку они являются ведущими для института и по утвержденным основным направлениям научных исследований, то естественно, что особой динамики в их развитии не наблюдается. Число работ по коррозии возрастает, динамика же других направлений четко связана с организационными мероприятиями, проведенными в институте $\left[{ }^{2}\right]$.

По библиографическим ссылкам можно следить и за изменениями в к олле к т в н о с и работы ученых. Общая тенденция в последние десятилетия, особенно в области естественных и технических наук, это постоянное увеличение коллективности работы ученых и постепенное уменьшение количества опубликованных работ, написанных единолично, одним автором. Динамика коллективности авторов в научных публикациях НИИсланцев приведена на рис. 3. Несмотря на то, что доля работ, написанных одним автором, снизилась с 45,5\% в 1961-1965 гг. до $27,0 \%$ в $1971-1975$ гг., это снижение не настолько резкое, как в ИХ и ТГУ, а удельный вес работ, написанных одним автором, довольно высокий - 33,8\%. Двумя авторами написано 29,6\% работ, тремя $18,5 \%$. Примерно одинаковая доля работ написана четырьмя $(9,6 \%)$, пятью и более авторами $(8,5 \%)$. В последнее пятилетие удельный вес работ, написанных тремя и более авторами, возрос почти до $50 \%$.

Помимо анализа коллективности в авторстве, мы рассмотрели также,

Таблица 3

Частота авторства в публикациях НИИсланцев

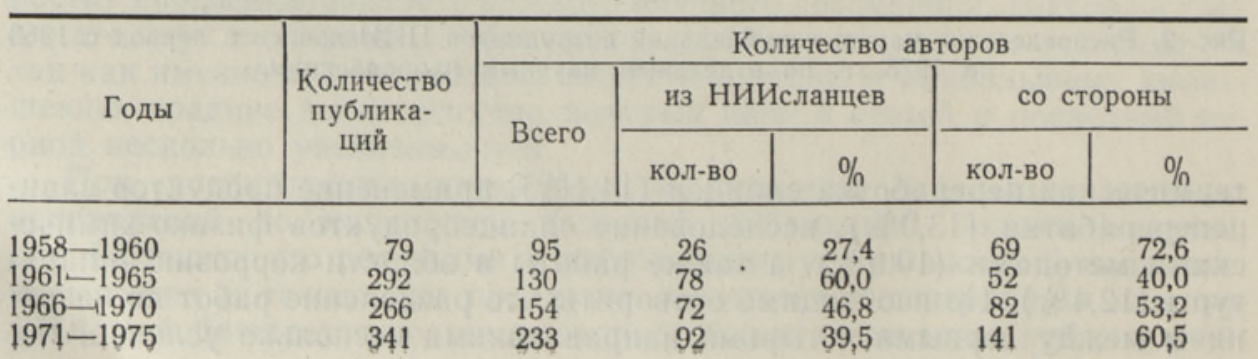


какая доля работ написана в соавторстве с сотрудниками других учреждений и какая часть авторов является сотрудниками НИИсланцев. Полученные результаты даны в табл. 3. Сотрудники других организаций участвовали в написании работ НИИсланцев (за весь период) в гораздо большей степени, чем в ИХ и ТГУ. Почти $1 / 3$ работ НИИсланцев написана в соавторстве с сотрудниками предприятий сланцевого бассейна, Таллинского политехнического института (ТПИ), ИХ и других учреждений. Количество авторов со стороны среди всех авторов публикаций (273 чел., или $66,7 \%$ ) намного превышает число авторов публикаций самого института (136 чел., или $33,3 \%$ ), - как в целом за весь период, так и в отдельные отрезки времени (табл. 3).

При рассмотрении издания работ сотрудников НИИсланщев выяснилось, что $78,5 \%$ из них изданы в республиканской печати, $21,0 \%$ - во всесоюзной и/лишь $0,5 \%$ - за границей (рис. 4). Эти цифры несколько условны, так как мы считали «Труды» института песпубликанским изданием, а на самом деле они издавались как в ЭССР. так и в Ленинграде. а ведомство - всесоюзное. «Сланцевые» проблемы, как известно, тесно связаны с республикой, так как горючие сланцы - основное природное богатство Эстонии. В целях более широкой гласности следовало бы увеличить количество работ, публикуемых в центральных изданиях или за границей. Обобщающие и теоретические работы следовало бы направлять в солидные журналы.

При рассмотрении тво рческой а к ти в ности сотрудников мы получили такие же закономерности, что и для ИХ и ТГУ: выделяется группа высокопродуктивных ученых $(10-15 \%)$, а большинство потенциальных авторов, т. е. сотрудников с высшим образованием или низкопродуктивно или же вообще не имеет публикаций. Так, из 291 сотрудника с высшим образованием. которые проработали в институте 1 год и более, имеют публикации 136 человек, или $46,7 \%$ (в ИХ $-57,5 \%$, в ТГУ $-77,8 \%)$. Из них по одной опубликованной работе имеют $24 \mathrm{co}$ трудника, более 50 работ опубликовали только 5 человек.

Результаты анализа частоты авторства (среднее количество работ в год, в составлении которых автор принимал участие) приведены на рис. $5: 30.1 \%$ авторов участвовали в составлении менее, чем 0,5 работы в год. $19,1 \%$ - от 0.5 до $0,99,21.3 \%$ - от 1,0 до $1,49,5,9 \%$ - от 1,5 до $1,99,9.6 \%$ - от 2,0 до 2,99 и $14,0 \%$ - в составлении более 3 работ в год. Самый высокий показатель - это 8,67 работы в среднем в год. Более 3 работ в год написали 19 сотрудников (это болыше, чем в ИХ за более длительный срок), менее 1 работы - 67 человек. Высокопродуктивными ( 2 и более работ в год) можно считать 32 сотрудника НИИсланцев, или $23,6 \%$ от рассматриваемого контингента, что намного больше, чем в ИХ $(8,6 \%)$.

В наших работах $\left[{ }^{3,4}\right]$ проанализирован еше один количественный аспект развития химической науки в Әстонской ССР, отражающий распространение результатов работ и идей ученых-химиков Эстонии по отдельным научным направлениям. Это - цитируемость опубликованных работ по отдельным направлениям. Научные направления сгруппированы по организационному приншипу по 5 учреждениям, в которых рабогают авторы цитируемых работ. Анализ провелен на основе издаваемого в США «Индекса научных ссылок» за 1965-1976 гг.

K сожалению, отклики на работы сотрудников с учеными степенями НИИсланцев в рассматриваемом издании самые немногочисленные, по сравнению со всеми учреждениями химического профиля Эстонской ССР. За этот период имеются ссылки в общей сложности на 23 работы ученых НИИсланцев (4,7\% всех цитируемых работ химиков ЭССР), 


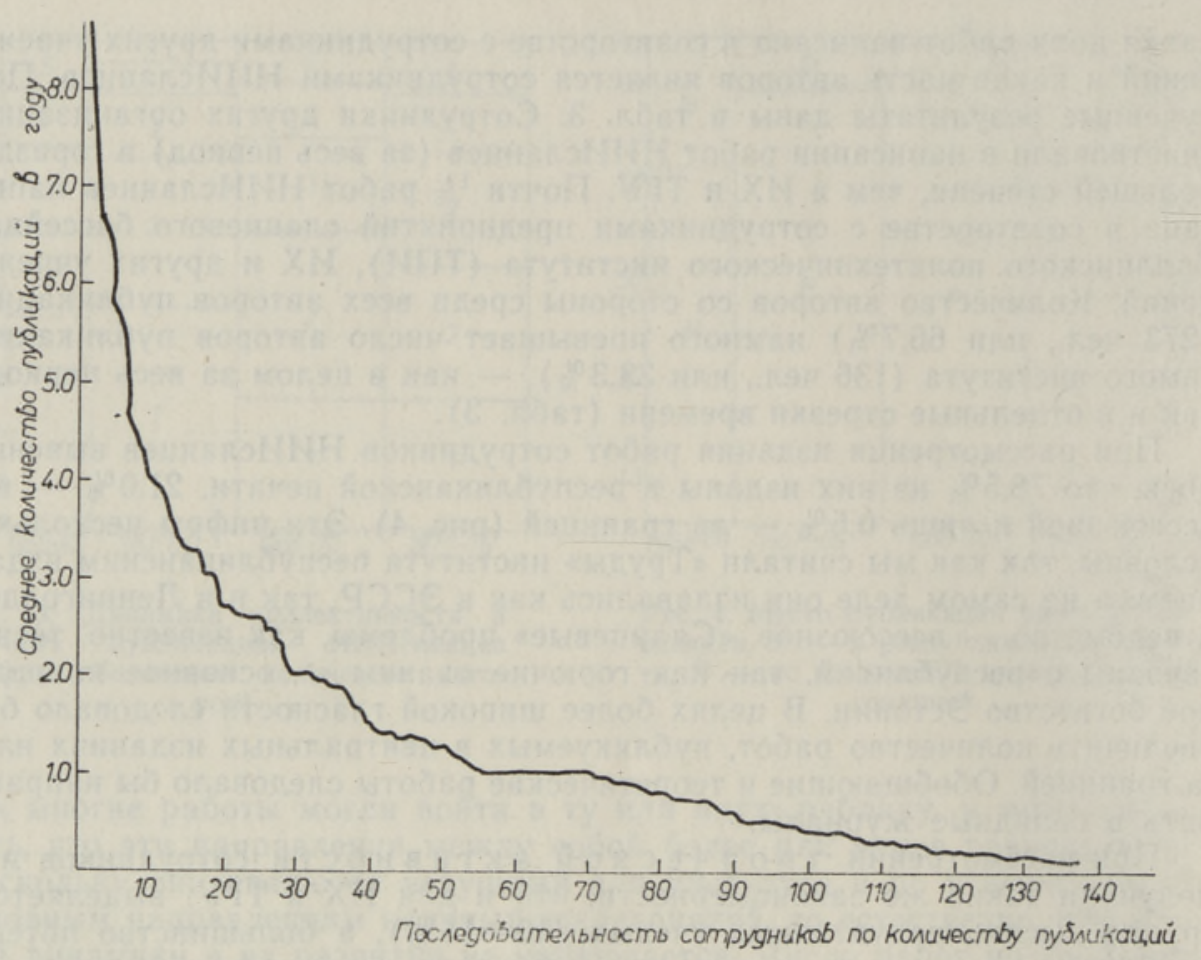

Рис. 5. Частота авторства в научных публикациях сотрудников НИИсланцев.

количество ссылок на них 29 (1,4\% от всех ссылок по Эстонской ССР). Ведущим направлением этого учреждения, заслуживающим внимание коллег как в нашей стране, так и за рубежом, является исследование сланцепродуктов (в первую очередь алкилрезорцинов) физико-химическими методами, на которое приходится 24 ссылки $(1,1 \%$ от всех ссылок по Әстонской ССР). Сканируются 18 работ $(3,7 \%$ от цитируемых работ химиков ЭССР). По количеству публикаций это направление стоит среди разрабатываемых в институте на пятом месте (107 наименований).

Анализ цитируемости работ химиков ЭССР показал, что интерес научной общественности к работам прикладного характера значительно ниже, чем к теоретическим и фундаментальным исследованиям. А работы по химии и технологии горючих сланцев все меньше привлекают внимание коллег как в нашей стране, так и за ее пределами.

Как следует из нашего анализа, НИИсланцев в настоящее время является самым крупным, достаточно сильным и продуктивным научным учреждением химического профиля в нашей республике. За последние годы институт сумел подготовить квалифицированные научные кадры. Сотрудниками этого института разработано множество оригинальных методов и технологических процессов переработки и использования основного природного богатства республики - горючего сланцакукерсита. НИИсланцев - единственное профилирующее научно-исследовательское учреждение по переработке сланцев в нашей стране. K настоящему времени он является уже достаточно «зрелым» для вы- 
движения и решения любых проблем, содержащихся в таких сложных и капризных объектах исследований, как горючий сланец-кукерсит и продукты его переработки. Поэтому, на наш взгляд, наступило время «качественного скачка», время обобщений, теоретической проработки накопленных нашими химиками материалов и знаний в данной области, некоторого расширения тематики института в более «фундаментальную» сторону. Тем более, что в других научно-исследовательских учреждениях химического профиля республики, в которых еще в середине 1960-х гг. «сланцевая» тематика сыграла значительную роль, в настоящее время этим уникальным горючим ископаемым занимаются лишь единичные группы исследователей. Выполнение текущих локальных потребностей и заказов сланцеперерабатывающей промышленности, которая в настоящее время у нас ориентируется, в первую очередь, на топливные, а не на химические продукты, не может обеспечивать высокого научного уровня проводимых в институте исследований. А что еще важнее (как для перспектив развития сланцехимической промышленности нашей республики, так и в нашей стране в целом, а также за границей): утилитарный, ограниченно технологический подход к научным и научноприкладным проблемам препятствует разработке пр и н ц и и а л ь н о но в ы х методов и процессов переработки и использования этого ценнейшего горючего ископаемого, основного источника органического сырья будущего.

\section{ЛИТЕРА Т РА}

1. П а т а Э. Горючие сланцы Прибалтийского месторождения. Библиография, тт. I, II (1777-1967). Таллин, 1968; тт. I, III (1777-1968). Таллин, 1970.

2. М артин н он Х. Формирование научных кадров НИИсланцев (1958-1975 гг.). Изв. АН ЭССР. Хим., 1979, т. 28, № 1, с. 55-62.

3. М а р ти н сон Х. Анализ цитируемости научных публикаций химиков Эстонской ССР. - В кн.: Вопросы истории Тартуского университета. (Материалы комиссии истории университета), т. V. Тарту, (1977, с. 185-196.

4. М а рт и н сон Х. Р. Анализ цитируемости научных публикаций как способ определения значимости и распространения результатов исследований. (По материалам химической науки Эстонской ССР), - В кн.: Из истории естествознания и техники Прибалтики, т. VI. Рига (в печати).

Ннститут химии

Академии наук Эстонской ССР
Поступила в редакцию 10/III 1978 